\title{
Тренажер техники чтения
}

Усинская Е.Т., ученица, МОУ Информационно-технологический лицей №24, 2. Нерюнгри

\section{Научные руководители: учитель робототехники Дёминов С.И., педагог дополнительного образования Миколайчук В.А., учитель информатики Усинская Т.С.}

Под руководством педагогов Информационно-технологического лицея г. Нерюнгри им. Е.А. Варшавского ученицей третьего класса создан тренажер для отработки техники чтения, используемый на занятиях в начальной школе, а также создана мобильная переносная версия данного тренажера.

Ключевые слова: Техника, чтение, тренажер, таймер, сборка.

Актуальность. Для того чтобы хорошо учится, надо много читать. И читать быстро. А для этого необходимо читать каждый день хотя бы 15 минут, тогда и скорость чтения повысится. Для этого было решено создать тренажер для чтения, который объединяет в себе подставку для книги и таймер. Возникнет вопрос, а почему просто не использовать обыкновенные часы или часы в телефоне? Но ведь иногда стоит открыть телефон, и ты уже отвлекаешься на звонки, игры, сообщения и т.д. А подставка с таймером это полезно и развивает самостоятельность. Поставил книгу, нажал кнопку таймера и читай, пока не прозвучит сигнал.

Гипотеза: Возможно, ли создать тренажер для отработки навыков чтения из конструктора Lego.

Цель работы: создание тренажера для чтения книг.

Задачи:

1. Собрать модель подставки из конструктора Lego c возможностью перелистывания страниц книги;

2. Разработать программу для таймера на основе блока Lego NXT;

3. Собрать мобильную версию подставки для использования на уроках

4. Провести испытания.

Новизна исследования: использование на занятиях и дома данного тренажера позволит улучшить навыки и скорость чтения.

Одна из важнейших задач начальной школы - формирование у ребенка навыка чтения, который является фундаментом всего последующего образования. Закончив первый класс и перейдя во второй, многие дети испытывают трудности при чтении, пропускают, заменяют, переставляют буквы и слоги, у них возникают проблемы при слогослиянии и другие ошибки, создающие сложности понимания прочитанного.

Ребята нервничают и переживают. В результате у них складывается негативное отношение к процессу чтения.

Если подобные нарушения вовремя не исправить, то в дальнейшем они вызовут трудности общения с окружающими и повлекут за собой определенные изменения личности в цепи развития ребенок - подросток - взрослый, т.е. приведут к возникновению у школьника закомплексованности, мешая ему учиться, в полной мере раскрыть свои природные способности и интеллектуальные возможности. 
После того как ребенок усвоил правила чтения букв, начинается работа по совершенствованию техники чтения. Она проводится на уроках классного и внеклассного чтения. Однако без помощи родителей и тренировок дома навык чтения развивается плохо и медленно.

Навык чтения складывается из смыслового и технического факторов. Техника чтения - это способ чтения, его правильность, скорость, выразительность. Каждый из данных компонентов, как и их совокупность, подчинен пониманию прочитанного. Ведь, собственно, и главная цель чтения - извлечь информацию, заключенную в тексте.

Скорость.

К сожалению, некоторые учителя и родители направляют всю свою энергию на борьбу за количество слов в минуту.

Скорость чтения действительно важна, но если ребенок, прочитав 100 слов за 60 секунд, допустил 10 ошибок, не сделав ни одной паузы даже на границе предложений, и не может рассказать о том, что он прочитал, то кому нужно такое «чтение»?

Поэтому не спешите радоваться высокой скорости чтения, если она сочетается с ошибками. Занимаясь дома, просите ребенка читать медленнее, но без ошибок.

Сознательность

Самое важное качество чтения - сознательность. Она предполагает понимание прочитанного, причем на первых порах - лишь его предметно фактической стороны (буквальное понимание), а затем уже и подтекста, метафор, авторского отношения, юмора, иронии, общей идеи текста.

Выразительность

С сознательностью чтения тесно связана его выразительность. Если ребенок не делает паузы, не отделяет одно предложение от другого, ему крайне нелегко разобраться в содержании, поскольку при таком чтении связи между отдельными словами, словосочетаниями и предложениями безнадежно теряются.

С другой стороны, если он понимает каждое прочитанное слово, в своем сознании соединяет его с предыдущими, ему легче следить за развитием мысли и соблюдать необходимые паузы и интонацию. Таким образом, сознательность и выразительность не могут существовать друг без друга: соблюдение знаков препинания помогает верно, расставить логические ударения и разобраться в содержании, а понимание смысла, в свою очередь, повышает выразительность чтения.

Правильность.

С первых шагов следует обращать внимание на правильность чтения. Не пропускайте ошибки, просите ребенка перечитать еще раз, как написано, выполняйте специальные упражнения.

Не жалейте времени на работу над правильностью чтения, поскольку она самым непосредственным образом связана с грамотностью письма. Так называемой врожденной грамотностью обладают не те дети, которые много читают, а те, которые читают правильно.

К сожалению, в современном обществе теряется ценность владения правильным русским языком. Появляются двойные стандарты расстановки ударения при произношении слов. Использование сокращения при написании сообщения ведет к безграмотности и сокращению словарного запаса носителя языка. На фоне информатизации современного общества теряется интерес к книгам и чтению в целом, аудитория, посещающая библиотеки, к сожалению, за последние 10 лет сократилась в двадцать раз. 


\section{1 Этап. Сборка модели тренажера.}

При сборке модели тренажера использовался конструктор Lego. Lego - серия игрушек, представляющие собой наборы деталей для сборки и моделирования разнообразных предметов. Основным продуктом компании LEGO являются разноцветные пластмассовые кирпичики, маленькие фигурки и т. д. Из LEGO можно

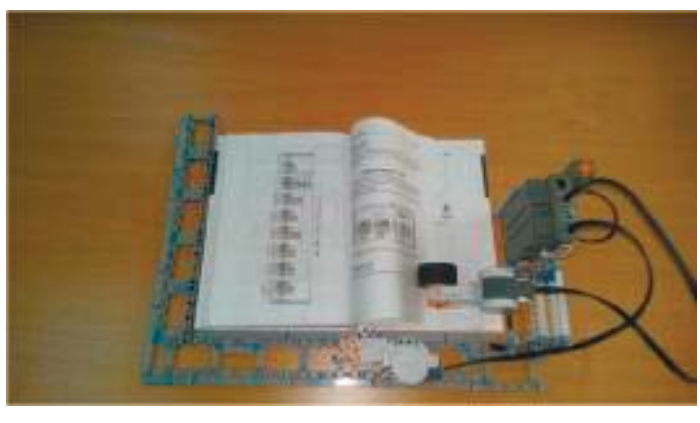
собрать такие объекты, как транспортные средства, здания, а также движущихся роботов. Все, что построено, затем можно разобрать, а детали использовать для создания других объектов.

Приступаем к сборке тренажера: Устанавливаем блок Lego NXT. К блоку подключаем два сервомотора, один из которых с помощью колеса будет переворачивать страницы читаемой книги, а второй в случае необходимости, с помощью рычага, доворачивать лист. Собираем конструкцию для расположения на ней книги и крепим к конструкции блок NXT и сервомоторы. Программируем блок в среде LEGO Mindstorm NXT. Проводим испытания.

\section{2. Этап. Разработка программы для таймера на основе блока Lego NXT}

При разработке программы для таймера использовалось приложение Lego Mindstorms NXT. Данное приложение позволяет создавать программы различной сложности для конструкторов серии Lego Mindstorms NXT. Таймер в тренажере нужен для того, чтобы можно было установить определенное время для чтения. Используя среду программирования Lego Mindstorms NXT и палитры инструментов создаем программу «15minytka».

В школе иногда проверяют технику чтения за 1 минуту. Конечно, дома можно на телефоне засекать время, но если ты сам читаешь и проверяешь себя, то это не очень удобно. Секундомер не подает сигнал, а значит, читаешь и одновременно держишь взгляд на циферблате. Для самопроверки техники чтения создана программа minyta1.

3 Этап. Сборка мобильной версии подставки для использования на уроках

Для использования тренажера на уроках при проверке техники чтения было решено создать мобильную версию подставки.

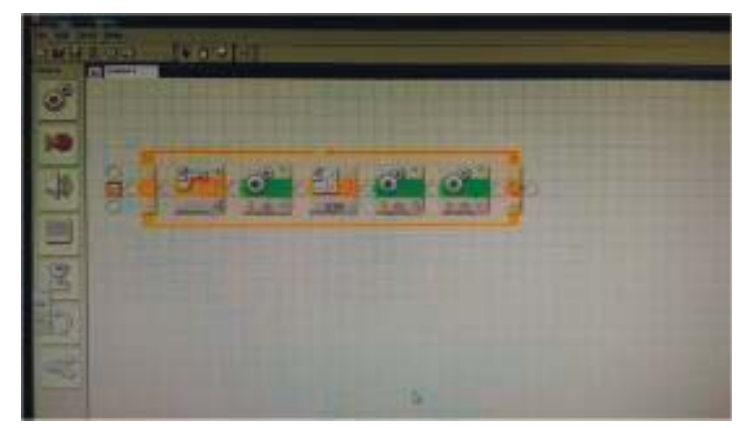

В ходе исследовательской работы была

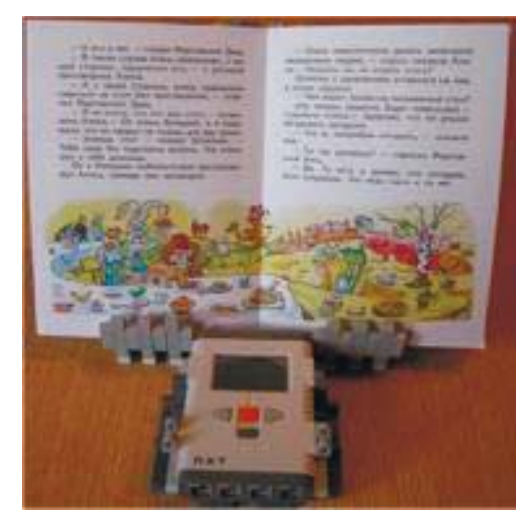

создана действующая модель тренажера для отработки навыков чтения с простым алгоритмом работы, а также создана мобильная версия, которая на сегодняшний день применяется на уроках литературы в начальной школе Информационнотехнологического лицея №24 им. Е.А.Варшавского г. Нерюнгри. В дальнейшем планируется создать инструкцию по сбору данного тренажера в программе Lego Digital 
Design v4.3 чтобы разработанный мною тренажер смогли использовать в других школах.

\title{
Список литературы:
}

1. Скрытые ресурсы мозга. Руководство по правильной эксплуатации, или Как повысить свой интеллект, развить интуицию и улучшить память./ Христиан Грюнинг, Астрель, М., 2012

2. https://ru.wikipedia.org/wiki/Lego

3. https://ru.wikipedia.org/wiki/Tехника_чтения

4. http://www.goagetaway.com/page/tehnika-chtenija

5. https://ProRobot.ru

6. http://ldd.lego.com/ru-ru/download

\section{Проектирование информационной системы для салона автомобилей}

\author{
Цыдыпова Е.Г., студентка, \\ Технический институт (филиал) \\ Северо-Восточного федерального университета, \\ 2. Нерюнгри \\ E-mail: cydypovae@mail.ru
}

Научный руководитель: к.т.н., доцент Похорукова М.Ю.

Большой выбор автомобилей, предлагаемых к продаже, необходимость хранения данных производителей, поставщиков и покупателей усложняют задачу учета поставок, продаж и остатков автомобилей в автомагазине. Ручная обработка этих данных не позволяет получить оперативную информацию и является довольно трудоемким процессом, поэтому появляется необходимость применения баз данных для учета автомобилей в автосалоне.

Разработка информационной системы, учитывающей специфику конкретного автосалона, позволит учесть все особенности процесса реализации автомобилей в нем и повысить эффективность деятельности автосалона в целом.

Выделим следующие базовые сущности:

- автомобили (название, цвет, кузов, мощность, объём двигателя, дата выпуска, расход топлива);

- покупатели (№ паспорта, серия, фамилия, имя, отчество, адрес, телефон);

- продажи (дата, стоимость);

- персонал предприятия (ФИО, оклад, должность, адрес, телефоны, стаж).

Необходимо предусмотреть возможность добавления, изменения и удаления записей, поиска сведений о клиентах, сотрудниках или автомобилях. Следует также выдвинуть некоторые требования, которым должен соответствовать создаваемый программный продукт:

- программа должна быть понятна любому пользователю ПК;

- программа должна работать на любых ЭВМ, на которых возможна работа с реляционными базами данных; 